\title{
Clinicopathological significance of WIF1 hypermethylation in NSCLC, a meta-analysis and literature review
}

\author{
Hao Guo ${ }^{1, *}$, Shuni Zhou ${ }^{2, *}$, Lili Tan ${ }^{1}$, Xiaoyu Wu ${ }^{3}$, Zhenfeng Wu ${ }^{3}$, Ruizhi Ran ${ }^{1}$ \\ ${ }^{1}$ Department of Oncology, The Central Hospital of Enshi Tujia and Miao Autonomous Prefacture, Enshi, Hubei 445000, China \\ ${ }^{2}$ Department of Chinese Medicine and Cardiology, The Central Hospital of Enshi Tujia and Miao Autonomous Prefacture, \\ Enshi, Hubei 445000, China \\ ${ }^{3}$ Surgical Oncology, Affiliated Hospital of Nanjing University of Traditional Chinese Medicine, 1 Nanjing 210029, China \\ *These authors contributed equally to this work
}

Correspondence to: Ruizhi Ran, email: ruizhiran56@hotmail.com

Keywords: NSCLC, WIF-1, methylation, tumor suppressor gene, drug target

Received: September 12, $2016 \quad$ Accepted: November 15, $2016 \quad$ Published: November 29, 2016

\begin{abstract}
Methylation of the WIF-1 gene can lead to the loss of WIF-1 expression which has been observed in numerous types of cancer including NSCLC. However, the association and clinicopathological significance between WIF-1 promoter hypermethylation and NSCLC remains unclear. In the present study, we performed a meta-analysis to evaluate the clinicopathological significance of WIF-1 hypermethylation in NSCLC. A systematic literature search was carried out using Pubmed, EMBASE, Web of Science and CNKI. The Cochrane software Review manager 5.2 was used. The frequency of WIF-1 hypermethylation was significantly increased in NSCLC compared with normal lung tissue; the pooled OR was 8.67 with $95 \%$ CI $1.64-45.88, p=0.01$. The rate of WIF-1 hypermethylation was higher in SCC than in AC, OR was 1.74 with $95 \%$ CI 0.97-3.11, $p=0.06$. In addition, WIF-1 loss was correlated with low 5-year survival rate. In summary, WIF-1 hypermethylation is a potential biomarker for diagnosis of NSCLC. WIF-1 hypermethylation is predominant in squamous cell carcinoma (SCC), suggesting that WIF-1 methylation contributes to the development of NSCLC, especially SCC.
\end{abstract}

\section{INTRODUCTION}

Lung cancer has been the leading cause of cancerrelated mortality worldwide. [1] Lung cancer can be classified two major histological groups, small cell cancer and non-small cell lung cancer (NSCLC). NSCLC can be divided into adenocarcinoma (AC), squamous cell carcinoma (SCC), large cell carcinoma and others. [2] The overall 5-year survival rate of NSCLC remains less than $18 \%$, [3] because a high proportion of NSCLCs are diagnosed at advanced stages. Therefore, it is particularly important to identify molecular markers for early diagnosis and determining prognosis.

Aberrant activation of the Wingless-type protein (Wnt) signaling pathways plays a very important role in the development of a variety of human cancers such as head and neck carcinoma, [4] melanoma, [5] colorectal cancer, [6, 7] and leukemia. [8] Previous evidence indicates that the inhibition of Wnt-1 induces apoptosis and suppresses tumor growth in lung cancer cell lines. [9-12] Wnt antagonists includes the secreted frizzledrelated protein (sFRP) family, Wnt inhibitory factor-1 (WIF-1), and Cerberus, [13] Disabled 2 (Dab2) [14] and Dickkof (DKK) family [15]. WIF-1 has been identified as an important Wnt antagonist which inhibits Wnt/ $\beta$ catenin signaling by directly binding to Wnt proteins. Methylation of the WIF-1 gene can lead to the loss of WIF-1 expression which has been observed in numerous types of cancer including NSCLC. [16-20] However, the association and clinicopathological significance between WIF-1 promoter hypermethylation and NSCLC remains unclear. In this study, we aim to systematically investigate the clinicopathological significance of WIF-1 promoter hypermethylation and NSCLC and quantify the association between WIF-1 promoter hypermethylation and NSCLC using meta-analysis 
methods. In addition, we summarize these findings and discuss the tumor suppressor function, as well as the clinicopathological significance of WIF-1 in NSCLC.

\section{RESULTS}

Flow chart for study selection is reported in Figure 1. There were four relevant articles available for metaanalysis, which included 392 patients (Table 1, Table 2).

The quality of each study was assessed with the Newcastle Ottawa Quality Assessment Scale (NOQAS). Of the studies, two scored eight points, one scored seven points and one scored six points. Hence, the studies were of a relatively high quality (data not shown).

The frequency of $W I F-1$ hypermethylation was significantly higher in NSCLC than in normal lung tissue, the pooled OR was 8.67 with $95 \%$ CI $1.64-45.88, z=2.54$, $p=0.01$ (Figure 2). The rate of WIF-1 hypermethylation was increased in SCC compared with AC, closely approaching the statistical significance, OR was 1.74 with $95 \%$ CI $0.97-3.11, \mathrm{z}=1.86, p=0.06$ (Figure 3). The rate of WIF-1 hypermethylation was not significantly associated with smoking behavior, OR was 1.54 with $95 \%$ CI $0.81-2.91, \mathrm{z}=1.33, p=0.18$ (Figure 4).
Two studies $[9,20]$ investigated the correlation between WIF-1 expression or methylation status and 5 -year overall survival, indicating that NSCLC patients with low WIF-1 expression or WIF-1 positive methylation were found to have a significantly lower rate of 5-year overall survival compared to the patients with high WIF-1 expression or WIF-1 negative methylation in their tumor tissues (Figure 5).

A sensitivity analysis was conducted by removing one study from the meta-analysis at a time; the overall results were not significantly affected. The pooled ORs were not significantly changed, indicating the stability of our analyses. The funnel plots were largely symmetrical (Figure 6A, 6B, 6C), suggesting there were no publication biases in the meta-analysis of $W I F-1$ methylation status between NSCLC and normal lung tissue, as well as WIF-1 methylation status between AC and SCC respectively.

\section{DISCUSSION}

Wnt signaling has been shown to control diverse biological processes and functions, including embryonic development, tissue regeneration, hematopoiesis, survival, cellular proliferation, and differentiation.

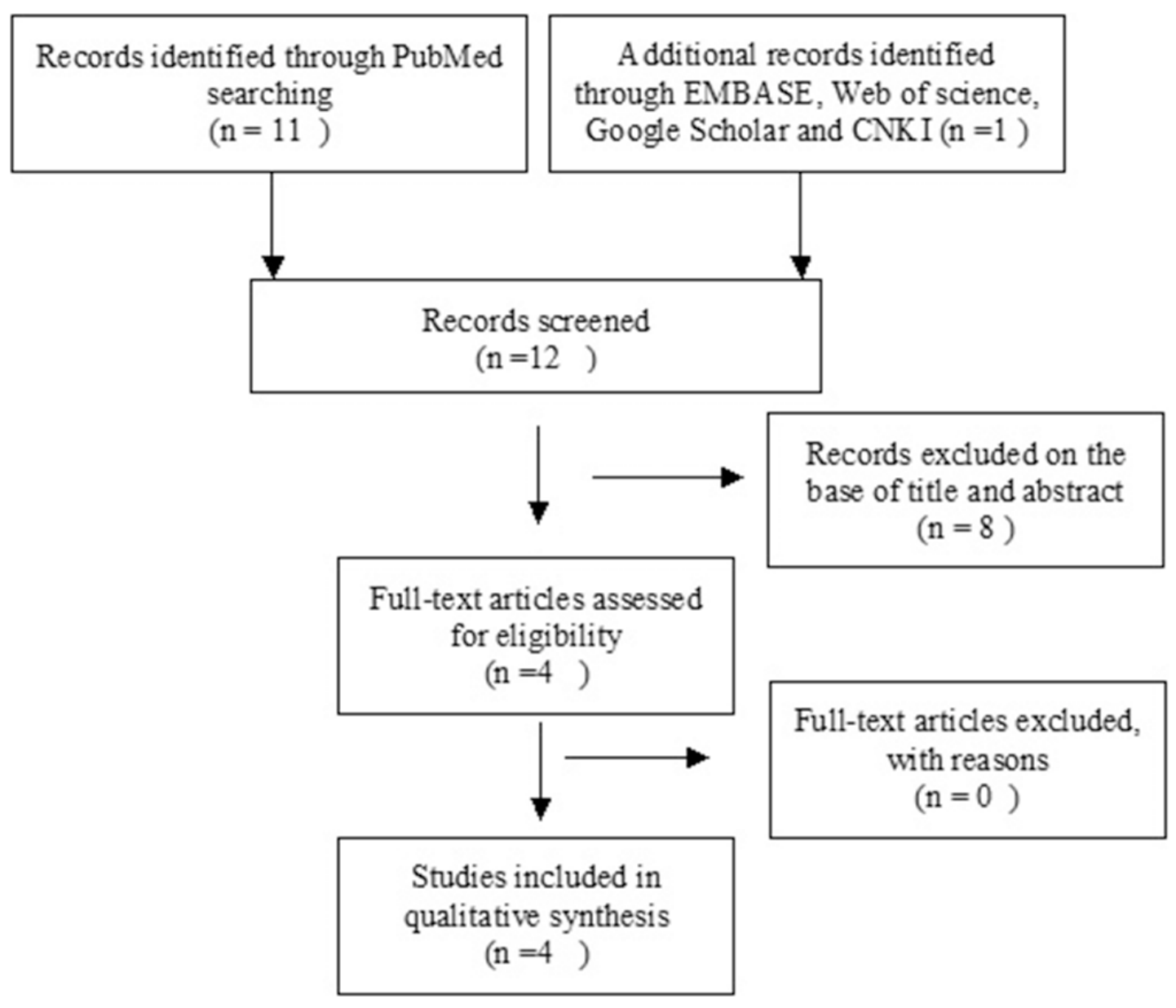

Figure 1: Schematic flow diagram for selection of included studies. 
Table 1: All 12 studies identified through database searching

\begin{tabular}{|c|c|c|}
\hline Author & $\begin{array}{l}\text { Included/ } \\
\text { Excluded }\end{array}$ & Comments \\
\hline Xie et al. 2015 [33] & Excluded & $\begin{array}{l}\text { Norcantharidin inhibits Wnt signal pathway via promoter demethylation of WIF- } \\
1 \text { in human NSCLC. }\end{array}$ \\
\hline Xu et al. 2015 [34] & Excluded & $\begin{array}{l}\text { Bisdemethoxycurcumin effects on TGF- } \beta 1 \text { induced EMT in NSCLC are mediated } \\
\text { through WIF-1 }\end{array}$ \\
\hline Tan et al. 2013 [32] & Excluded & $\begin{array}{l}\text { miR-29s suppress the Wnt signaling pathway through demethylation of WIF-1 in } \\
\text { NSCLC. }\end{array}$ \\
\hline Liu et al. $2011[35]$ & Excluded & Hypomethylation effects of curcuminoid on $W I F-1$ promoter in NSCLC cell lines. \\
\hline Liu et al. 2011a [12] & Excluded & Hypomethylation agent induces apoptosis in human NSCLC \\
\hline Suzuki et al. 2010 [36] & Included & $\begin{array}{l}\text { Molecular Characterization of Chronic Obstructive Pulmonary Disease-Related } \\
\text { NSCLC through WIF-1 aberrant methylation and Alterations of EGFR Signaling. }\end{array}$ \\
\hline Gao et al. 2009 [37] & Excluded & $\begin{array}{l}\text { The role of Epigallocatechin-3- gallate in the reversal of } W I F-1 \text { promoter } \\
\text { methylation in NSCLC cell line }\end{array}$ \\
\hline Gao et al. 2009a [38] & Excluded & $\begin{array}{l}\text { Procaine and procainamide inhibit the Wnt canonical pathway by promoter } \\
\text { demethylation of } W I F-1 \text { in lung cancer cells }\end{array}$ \\
\hline Yoshino et al. 2009 [20] & Included & $\begin{array}{l}\text { Promoter hypermethylation of the } p 16 \text { and } W I F-1 \text { genes as an independent } \\
\text { prognostic marker in stage IA NSCLC. }\end{array}$ \\
\hline Yang et al. 2009 [39] & Excluded & $\begin{array}{l}\text { The role } W I F-1 \text { promoter hypermethylation in the diagnosis of NSCLC-related } \\
\text { malignant pleural effusion. }\end{array}$ \\
\hline Ren et al. 2007 [9] & Included & $\begin{array}{l}\text { The relationship between WIF-1, Gsk- } 3 \beta \text { and nm } 23-\mathrm{H} 1 \text { expression and the } \\
\text { prognosis in patient with non-small cell lung cancer. }\end{array}$ \\
\hline Mazieres et al. 2004 [19] & Included & Promoter Hypermethylation in Human lung cancer. \\
\hline
\end{tabular}

[21-23] There are several Wnt inhibitors, including sFRPs, [24] WIF-1, [25] Cerberus [26] and Dab2 that inhibit Wnt signaling by competing with the binding of Wnt proteins to the $\mathrm{Fz}$ receptor. [13, 27] Another group of Wnt inhibitors are the members of the Dkk family that inhibit Wnt signaling by binding to the LRP5/LRP6 component of the Wnt receptor complex. [13] Downregulation of WIF-1 has been demonstrated in several type cancers including NSCLC and has been observed by immunochemistry in $60 \%$ of breast cancers and $75 \%$ of lung cancers. [28] A few studies showed that $W I F-1$ silencing correlates with hypermethylation of its promoter in both cell lines and human NSCLC primary tissue; however, the rate of WIF-1 promoter hypermethylation in NSCLC was diverse. For the first time we conducted a meta-analysis to more precisely evaluate the rate of WIF-1 promoter hypermethylation in NSCLC and normal lung tissue. Our findings indicate the frequency of WIF-1 promoter hypermethylation was 8.67 times higher in NSCLC than in normal lung tissue. Therefore, WIF-1 promoter methylation could serve as a molecular diagnostic biomarker for NSCLC. On the other hand, since these are methylation marker, demethylation agents such as 5-Aza-2-deoxycitidine (5-AZA), an inhibitor of DNA methyltransferase can recover such epigenetic changes. [29, 30] In addition, miR-29 family members (which downregulate the DNA methyltransferases DNMT3A and DNMT3B), as well as demethylation agents decreased promoter methylation and increased expression of WIF-1, as a result, those agents suppressed tumor proliferation and induced apoptosis in lung cancer cell lines. [11, 12,31] Therefore, WIF-1 could be a novel drug target for the development of personalized therapy. Although further study is 
Table 2: Main characteristics of included studies

\begin{tabular}{|c|c|c|c|c|c|c|c|c|c|c|c|}
\hline \multirow[t]{2}{*}{ Author } & \multirow[t]{2}{*}{ Country } & \multicolumn{2}{|c|}{ Sample (M/T) } & \multirow{2}{*}{$\begin{array}{c}\text { Methylation } \\
\text { in NSCLC(\%) } \\
\text { Avg. 26.78\% }\end{array}$} & \multicolumn{2}{|c|}{$\begin{array}{c}\text { WIF1 Methylation } \\
(\mathrm{M} / \mathrm{T})\end{array}$} & \multicolumn{2}{|c|}{$\begin{array}{c}\text { WIF1 Methylation } \\
(\mathrm{M} / \mathrm{T})\end{array}$} & \multirow{2}{*}{$\begin{array}{c}\text { Wif1 } \\
\text { Expression } \\
\text { in NSCLC }\end{array}$} & \multirow[t]{2}{*}{$\begin{array}{l}\text { Methylation } \\
\text { site }\end{array}$} & \multirow[t]{2}{*}{ Methods } \\
\hline & & NSCLC & Normal & & Smoking & Non-smoking & Male & Female & & & \\
\hline Suzuki & Japan & $42 / 177$ & $4 / 80$ & 23.7 & $48 / 162$ & $14 / 67$ & $46 / 160$ & $16 / 69$ & N/A & Promoter & MSP \\
\hline Yoshino & Japan & $7 / 44$ & $2 / 32$ & 15.9 & $5 / 22$ & $2 / 10$ & $4 / 22$ & $3 / 22$ & N/A & Promoter & MSP \\
\hline Ren & China & N/A & N/A & & \multicolumn{2}{|r|}{ N/A } & \multicolumn{2}{|c|}{ N/A } & N/A & Promoter & MSP \\
\hline Mazieres & USA & $15 / 18$ & $0 / 18$ & 83.3 & \multicolumn{2}{|r|}{ N/A } & \multicolumn{2}{|c|}{ N/A } & $3 / 18$ & Promoter & MSP \\
\hline
\end{tabular}

Abbreviations: NSCLC: Non-small cell lung cancer, M: Methylation, T: Total, N/A: Not available, MSP: Methylation-specific PCR

\begin{tabular}{|c|c|c|c|c|c|c|c|c|c|c|}
\hline Study or Subgroup & \multicolumn{2}{|c|}{ NSCLC } & \multicolumn{2}{|c|}{ Normal lung tissue } & Weight & $\begin{array}{c}\text { Odds Ratio } \\
\text { M-H, Random, } 95 \% \mathrm{Cl}\end{array}$ & \multicolumn{3}{|c|}{$\begin{array}{c}\text { Odds Ratio } \\
\text { M-H, Random, } 95 \% \mathrm{Cl}\end{array}$} & \\
\hline Mazieres 2004 & 15 & 18 & 0 & 18 & $19.2 \%$ & $163.86[7.85,3422.30]$ & & & & $\vec{\longrightarrow}$ \\
\hline Suzuki 2010 & 62 & 229 & 4 & 80 & $45.1 \%$ & $7.05[2.48,20.09]$ & & & & \\
\hline Yoshino 2009 & 7 & 44 & 2 & 32 & $35.6 \%$ & $2.84[0.55,14.68]$ & & & & \\
\hline Total $(95 \% \mathrm{Cl})$ & & 291 & & 130 & $100.0 \%$ & $9.33[1.79,48.56]$ & & & & \\
\hline Total events & 84 & & 6 & & & & & & & \\
\hline
\end{tabular}

Figure 2: Forest plot for WIF-1 hypermethylation in NSCLC and non-neoplastic lung tissue. The squares represent the weight of individual study in the meta-analysis, the line width indicates the corresponding $95 \%$ CI, The diamond represents the pooled OR, and the width of diamond indicates $95 \% \mathrm{CI}$.

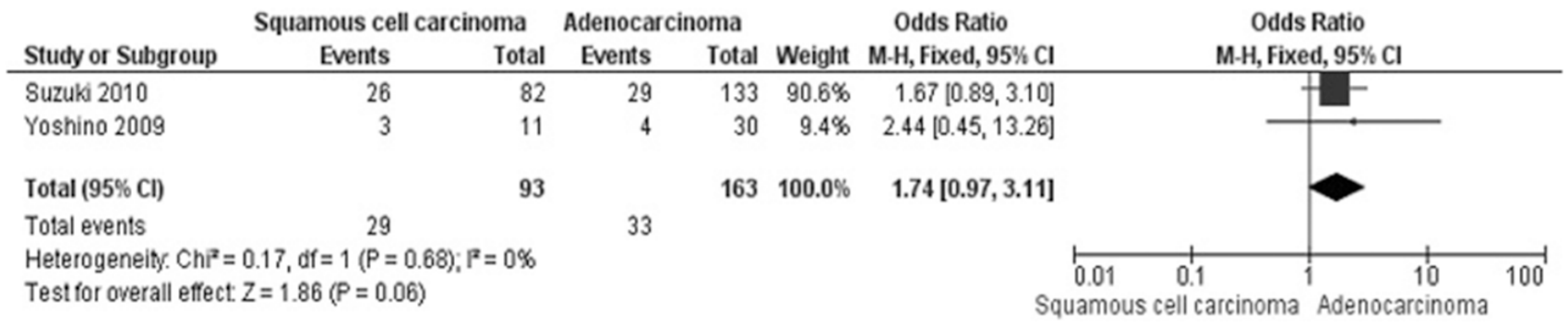

Figure 3: Forest plot for WIF-1 hypermethylation in AC and SCC. The squares represent the weight of individual study in the meta-analysis, the line width indicates the corresponding 95\% CI, The diamond represents the pooled OR, and the width of diamond indicates $95 \% \mathrm{CI}$.

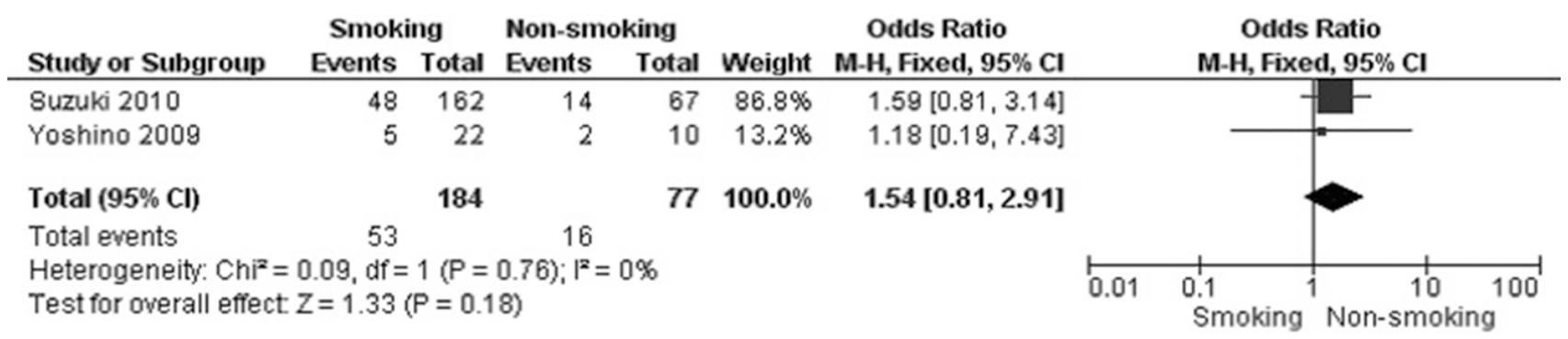

Figure 4: Forest plot for WIF-1 hypermethylation of NSCLC in smoking and non-smoking individual. The squares represent the weight of individual study in the meta-analysis, the line width indicates the corresponding $95 \%$ CI, The diamond represents the pooled OR, and the width of diamond indicates $95 \% \mathrm{CI}$. 
needed, our findings may contribute to the improvement of treatment and prognosis in patients with NSCLC.

In addition, our result showed that the frequency of WIF-1 hypermethylation was increased in SCC than in $\mathrm{AC}$, approaching more closely significance $(p=0.06)$.
The prevalence of WIF-1 hypermethylation in SCC may related to smoking behavior, as smoking is considered a risk factor for the development of SCC. However, WIF-1 hypermethylation was not significantly higher in smoking NSCLC patients. Our analysis was limited by

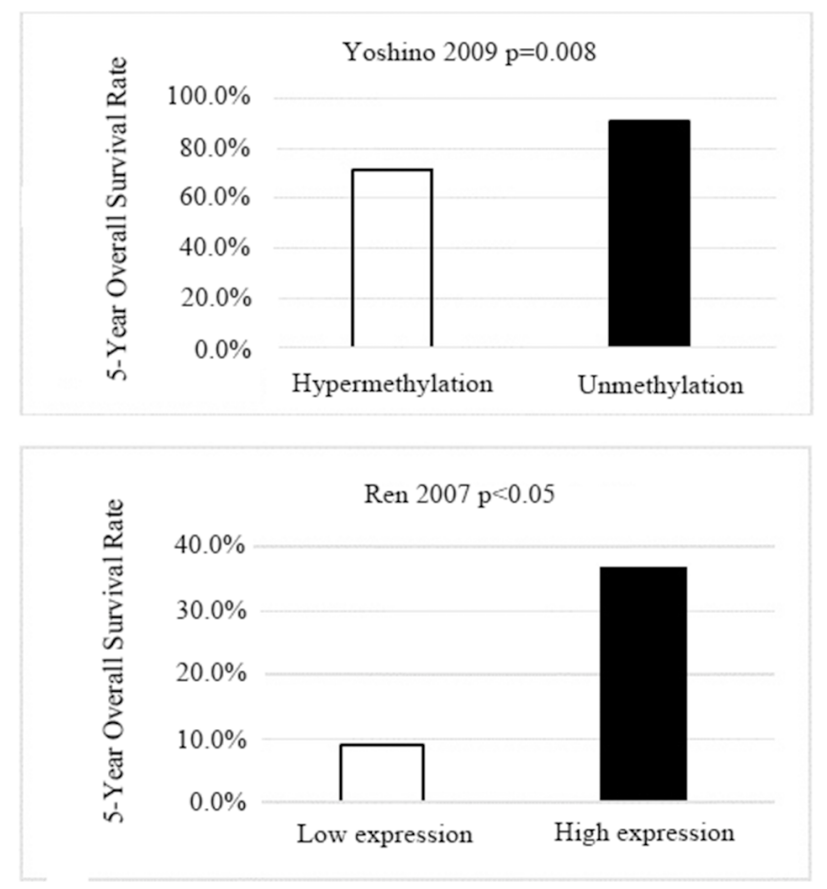

Figure 5: Charts for the association between WIF-1 expression or WIF-1 hypermethylation and 5-year survival rate.
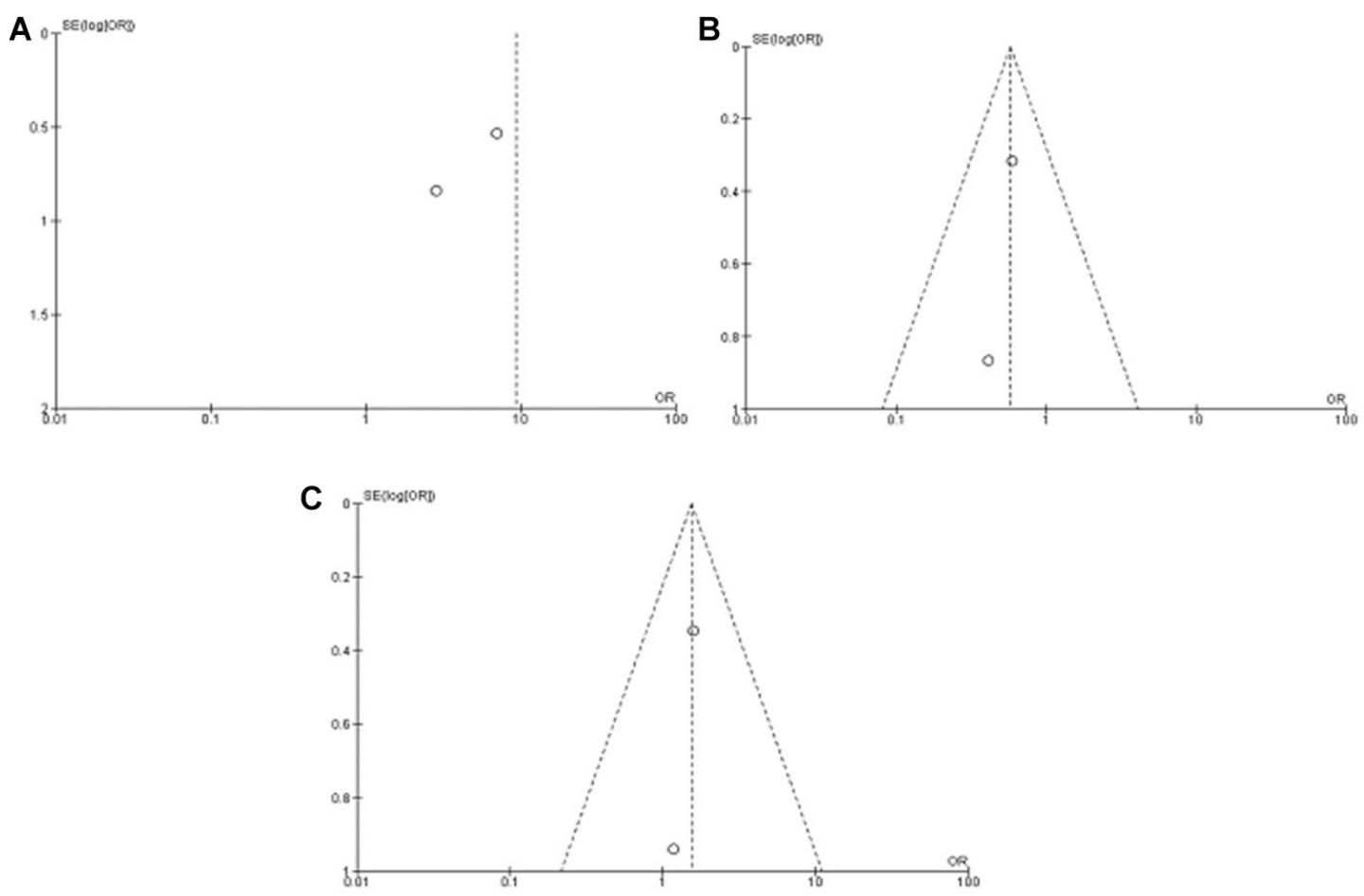

Figure 6: Funnel plot for publication bias. (A) WIF-1 hypermethylation in NSCLC and non-neoplastic lung tissue; (B) WIF-1 hypermethylation in AC and SCC; (C) WIF-1 hypermethylation of NSCLC in smoking and non-smoking individual. S.E., standard error; Area of the circle represents the weight of individual study. 
the small number of available studies. A large number of NSCLC patients are needed to more precisely evaluate the correlation between $W I F-1$ hypermethylation and smoking in the future.

Two studies [9, 20] showed that the loss of WIF-1 was correlated with the prognosis in patients with NSCLC; both studies revealed that the loss of WIF-1 was strongly associated with shorter 5-year survival. Yoshino et al. performed a multivariate analysis showing that $W I F-1$ hypermethylation was an independent prognostic factor in relapse-free survival after adjusting age, gender, tumor size and histology. Therefore, loss of WIF-1 may increase the recurrence potential and malignant feature of NSCLC. Suzuki et al. reported the hypermethylation of Wif1, sFRP1, sFRP5 and DKK was correlated with overall survival respectively in the univariate analysis. The silencing of other antagonists (such as sFRPs, Cerberus, Dab2 and Dkk ) could affect prognosis on patients with NSCLC concomitantly by the hypermethylation of WIF1. A further multivariate analysis involving Wif-1, sFRPs, Cerberus, Dab2 and Dkk are required to find out whether Wif-1 methylation is independently or concomitantly associated with the prognosis in patients with NSCLC.

The results should be interpreted in view of certain limitations. First, only four studies were included in the meta-analysis, heterogeneity existed in some analysis which we used random effect model instead of fix effect model. Second, the included studies were retrospective and not randomized, however, most of them were of sufficiently quality (Newcastle-Ottawa Scale $\geq 7$ ). Third, only studies in English and Chinese were included in the meta-analysis, eligible studies in other languages could be excluded. Fourth, smoker group was described as current and former smoker in one included study, [20] the finding could be confounded by former smoker. The result needs to be confirmed in more sensible way when more studies available.

In summary, the frequency of $W I F-1$ hypermethylation significantly increased in NSCLC tumor compare with normal lung tissue. WIF-1 gene is a potential marker for diagnosis of NSCLC and the prediction of prognosis in patients with NSCLC. WIF-1 hypermethylation is predominant in squamous cell carcinoma (SCC), suggesting that WIF-1 methylation contributes to the development of NSCLC, especially SCC.

\section{MATERIALS AND METHODS}

We conducted a meta-analysis in accordance with the PRISMA guideline (Checklist S1).

\section{Search strategy}

We performed a systematic electronic search in all available literature until July 2016 on PubMed, EMBASE, Web of Science and CNKI with no language limitations. We searched with the terms: "tumor or cancer or neoplasm or carcinoma" and "lung", "methylation", and "WIF-1 or Wnt inhibitory factor-1". Additional studies were identified through manually searching key journals and screening reference list of included studies. There were 11 articles identified from PubMed and one article from CNKI. A total of 12 articles were screened by article titles and abstracts.

\section{Selection criteria}

Inclusion criteria were as follows: 1) Studies that investigated the relationship between WIF-1 hypermethylation and the clinicopathological parameters of NSCLC; 2) WIF-1 hypermethylation evaluated in the primary NSCLC tissues; 3) Studies provided information to estimate hazard ratio (HR) about 5-year overall survival (OS) and 95\% confidence interval (CI). The studies were excluded based on the following criteria: 1) Reviews, case reports, letters, conference abstracts, editorials, expert opinion; 2) Studies in which same population or overlapping data were used.

\section{Data extraction and methodological assessment}

We reviewed and extracted data from eligible studies. Any disagreements were resolved through discussion until a consensus was reached. The following items were collected from each study: the first author name, year of publication, number of cases, histology types of tumors, methylation detection method, methylation rate, 5 -year overall survival rate. Data for study characteristics and clinical responses were summarized and organized into a table format.

For the methodological evaluation of the studies, we assessed and scored each publication independently according to the Newcastle Ottawa Quality Assessment Scale (NOQAS). The scale allocates a maximum of nine points for the quality of selection, comparability, exposure, and outcomes for study participants. The NOS scores ranged from 0 to 9 , and a study with a score of 7 or more indicates a good quality.

\section{Statistical analysis}

The meta-analysis was conducted using Review Manager 5.2 (Cochrane Collaboration, Software Update, Oxford, UK). Odds ratios (ORs) with its $95 \%$ confidence intervals were calculated. The $I^{2}$ statistics was used to examine the difference of study variability due to heterogeneity rather than chance, ranging from 0 to 100 percent. When the $I^{2}$ value was below $50 \%$, fixed effect model was used. When the $I^{2}$ value was $50 \%$ or greater, a random effect model was used. The frequency of $W I F-$ 1 hypermethylation was compared between normal lung tissue and NSCLC. In addition, we evaluated WIF-1 
methylation status in different histologic types of NSCLC as well as different smoking behavior. Two-sided $p$ values less than 0.05 were considered statistically significant. Publication bias was assessed by using a method reported by Egger et al. [32]

\section{ACKNOWLEDGMENTS}

There is no funding that supported this work.

\section{CONFLICTS OF INTEREST}

The authors declare that they have no conflicts of interest.

\section{REFERENCES}

1. World Health Organization. GLOBOCAN 2012: Estimated cancer incidence, mortality and prevalence worlwide in 2012. http://globocaniarcfr/Pages/fact_sheets_canceraspx. 2012.

2. Travis WD. Pathology of lung cancer. Clin Chest Med. 2011; 32:669-692.

3. Siegel R, Ma J, Zou Z, Jemal A. Cancer statistics, 2014. CA Cancer J Clin. 2014; 64:9-29.

4. Rhee CS, Sen M, Lu D, Wu C, Leoni L, Rubin J, Corr M, Carson DA. Wnt and frizzled receptors as potential targets for immunotherapy in head and neck squamous cell carcinomas. Oncogene. 2002; 21:6598-6605.

5. Weeraratna AT, Jiang Y, Hostetter G, Rosenblatt K, Duray P, Bittner M, Trent JM. Wnt5a signaling directly affects cell motility and invasion of metastatic melanoma. Cancer Cell. 2002; 1:279-288.

6. Morin PJ, Sparks AB, Korinek V, Barker N, Clevers H, Vogelstein B, Kinzler KW. Activation of beta-catenin-Tcf signaling in colon cancer by mutations in beta-catenin or APC. Science. 1997; 275:1787-1790.

7. Korinek V, Barker N, Morin PJ, van Wichen D, de Weger R, Kinzler KW, Vogelstein B, Clevers H. Constitutive transcriptional activation by a beta-catenin-Tcf complex in APC-/- colon carcinoma. Science. 1997; 275:1784-1787.

8. Lu D, Zhao Y, Tawatao R, Cottam HB, Sen M, Leoni LM, Kipps TJ, Corr M, Carson DA. Activation of the Wnt signaling pathway in chronic lymphocytic leukemia. Proc Natl Acad Sci USA. 2004; 101:3118-3123.

9. J R. The expression of WIF-1, Gsk-3 $\beta$ and nm23-H1 in NSCLC and its association with the prognosis of patients with NSCLC. Journal of SiChun University. 2007.

10. He B, You L, Uematsu K, Xu Z, Lee AY, Matsangou M, McCormick F, Jablons DM. A monoclonal antibody against Wnt-1 induces apoptosis in human cancer cells. Neoplasia. 2004; 6:7-14.

11. Jia Y, Yang Y, Brock MV, Zhan Q, Herman JG, Guo M. Epigenetic regulation of DACT2, a key component of the
Wnt signalling pathway in human lung cancer. J Pathol. 2013; 230:194-204.

12. Liu YL, Yang HP, Zhou XD, Gong L, Tang CL, Wang HJ. The hypomethylation agent bisdemethoxycurcumin acts on the WIF-1 promoter, inhibits the canonical Wnt pathway and induces apoptosis in human non-small-cell lung cancer. Curr Cancer Drug Targets. 2011; 11:1098-1110.

13. Mazieres J, He B, You L, Xu Z, Jablons DM. Wnt signaling in lung cancer. Cancer Lett. 2005; 222:1-10.

14. Takahashi-Yanaga F, Kahn M. Targeting Wnt signaling: can we safely eradicate cancer stem cells? Clin Cancer Res. 2010; 16:3153-3162.

15. Kawano Y, Kypta R. Secreted antagonists of the Wnt signalling pathway. J Cell Sci. 2003; 116:2627-2634.

16. Amiot A, Mansour H, Baumgaertner I, Delchier JC, Tournigand C, Furet JP, Carrau JP, Canoui-Poitrine F, Sobhani I, Marne CRCgoVD. The detection of the methylated Wif-1 gene is more accurate than a fecal occult blood test for colorectal cancer screening. PLoS One. 2014; 9:e99233.

17. Abdelmaksoud-Dammak R, Miladi-Abdennadher I, Saadallah-Kallel A, Khabir A, Sellami-Boudawara T, Frikha M, Daoud J, Mokdad-Gargouri R. Downregulation of WIF-1 and Wnt5a in patients with colorectal carcinoma: clinical significance. Tumour Biol. 2014; 35:7975-7982.

18. Paluszczak J, Hemmerling D, Kostrzewska-Poczekaj M, Jarmuz-Szymczak M, Grenman R, Wierzbicka M, BaerDubowska W. Frequent hypermethylation of WNT pathway genes in laryngeal squamous cell carcinomas. J Oral Pathol Med. 2014; 43:652-657.

19. Mazieres J, He B, You L, Xu Z, Lee AY, Mikami I, Reguart N, Rosell R, McCormick F, Jablons DM. Wnt inhibitory factor- 1 is silenced by promoter hypermethylation in human lung cancer. Cancer Res. 2004; 64:4717-4720.

20. Yoshino M, Suzuki M, Tian L, Moriya Y, Hoshino H, Okamoto T, Yoshida S, Shibuya K, Yoshino I. Promoter hypermethylation of the p16 and Wif-1 genes as an independent prognostic marker in stage IA non-small cell lung cancers. Int J Oncol. 2009; 35:1201-1209.

21. Prakash S, Swaminathan U. beta catenin in health: A review. J Oral Maxillofac Pathol. 2015; 19:230-238.

22. Clevers H. Wnt/beta-catenin signaling in development and disease. Cell. 2006; 127:469-480.

23. MacDonald BT, Tamai K, He X. Wnt/beta-catenin signaling: components, mechanisms, and diseases. Dev Cell. 2009; 17:9-26.

24. Rattner A, Hsieh JC, Smallwood PM, Gilbert DJ, Copeland NG, Jenkins NA, Nathans J. A family of secreted proteins contains homology to the cysteine-rich ligandbinding domain of frizzled receptors. Proc Natl Acad Sci USA. 1997; 94:2859-2863.

25. Hsieh JC, Kodjabachian L, Rebbert ML, Rattner A, Smallwood PM, Samos CH, Nusse R, Dawid IB, Nathans J. 
A new secreted protein that binds to Wnt proteins and inhibits their activities. Nature. 1999; 398:431-436.

26. Glinka A, Wu W, Onichtchouk D, Blumenstock C, Niehrs C. Head induction by simultaneous repression of Bmp and Wnt signalling in Xenopus. Nature. 1997; 389:517-519.

27. Arias AM, Brown AM, Brennan K. Wnt signalling: pathway or network? Curr Opin Genet Dev. 1999; 9:447-454.

28. Wissmann C, Wild PJ, Kaiser S, Roepcke S, Stoehr R, Woenckhaus M, Kristiansen G, Hsieh JC, Hofstaedter F, Hartmann A, Knuechel R, Rosenthal A, Pilarsky C. WIF1, a component of the Wnt pathway, is down-regulated in prostate, breast, lung, and bladder cancer. J Pathol. 2003; 201:204-212.

29. Karpf AR, Jones DA. Reactivating the expression of methylation silenced genes in human cancer. Oncogene. 2002; 21:5496-5503.

30. Nuovo GJ, Plaia TW, Belinsky SA, Baylin SB, Herman JG. In situ detection of the hypermethylation-induced inactivation of the p16 gene as an early event in oncogenesis. Proc Natl Acad Sci USA. 1999; 96:12754-12759.

31. Tan M, Wu J, Cai Y. Suppression of Wnt signaling by the miR-29 family is mediated by demethylation of WIF-1 in non-small-cell lung cancer. Biochem Biophys Res Commun. 2013; 438:673-679.

32. Egger M, Davey Smith G, Schneider M, Minder C. Bias in meta-analysis detected by a simple, graphical test. BMJ. 1997; 315:629-634.

33. Xie J, Zhang Y, Hu X, Lv R, Xiao D, Jiang L, Bao Q. Norcantharidin inhibits Wnt signal pathway via promoter demethylation of WIF-1 in human non-small cell lung cancer. Med Oncol. 2015; 32:145.
34. Xu JH, Yang HP, Zhou XD, Wang HJ, Gong L, Tang CL. Role of Wnt Inhibitory Factor-1 in Inhibition of Bisdemethoxycurcumin Mediated Epithelial-toMesenchymal Transition in Highly Metastatic Lung Cancer 95D Cells. Chin Med J. 2015; 128:1376-1383.

35. Liu YL, Yang HP, Gong L, Tang CL, Wang HJ. Hypomethylation effects of curcumin, demethoxycurcumin and bisdemethoxycurcumin on WIF-1 promoter in non-small cell lung cancer cell lines. Mol Med Rep. 2011; 4:675-679.

36. Suzuki M, Wada H, Yoshino M, Tian L, Shigematsu H, Suzuki H, Alaa M, Tamura H, Fujiwara T, Nagato K, Motohashi S, Moriya Y, Hoshino H, et al. Molecular characterization of chronic obstructive pulmonary diseaserelated non-small cell lung cancer through aberrant methylation and alterations of EGFR signaling. Ann Surg Oncol. 2010; 17:878-888.

37. Gao Z, Xu Z, Hung MS, Lin YC, Wang T, Gong M, Zhi X, Jablon DM, You L. Promoter demethylation of WIF-1 by epigallocatechin-3-gallate in lung cancer cells. Anticancer Res. 2009; 29:2025-2030.

38. Gao Z, Xu Z, Hung MS, Lin YC, Wang T, Gong M, Zhi X, Jablons DM, You L. Procaine and procainamide inhibit the Wnt canonical pathway by promoter demethylation of WIF-1 in lung cancer cells. Oncol Rep. 2009; 22:1479-1484.

39. Yang TM, Leu SW, Li JM, Hung MS, Lin CH, Lin YC, Huang TJ, Tsai YH, Yang CT. WIF-1 promoter region hypermethylation as an adjuvant diagnostic marker for nonsmall cell lung cancer-related malignant pleural effusions. J Cancer Res Clin Oncol. 2009; 135:919-924. 